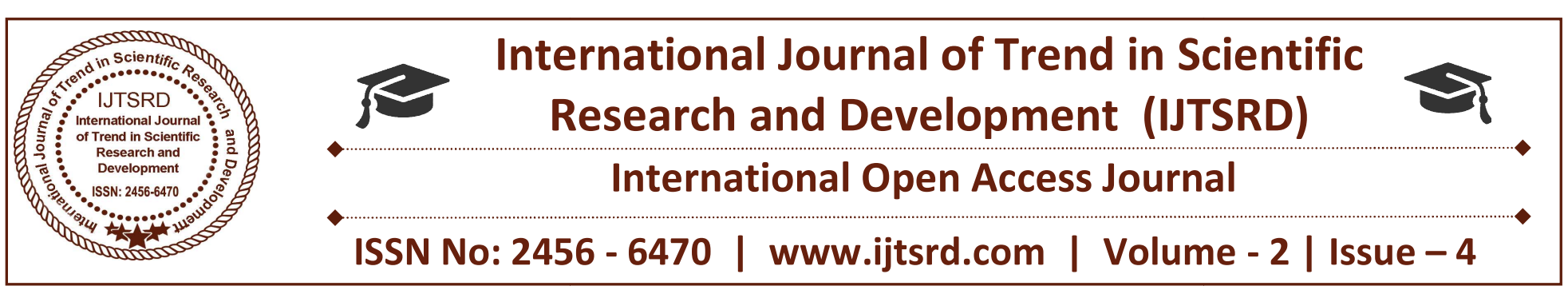

\title{
Awareness on Polycystic Ovarian Syndrome (PCOS) Among College Going Girls
}

\author{
Mrs. Meena Patangay, G. Akhila, Sritaja. M \\ Department of Nutrition, St.Ann's College for Women, \\ Mehdipatnam, Hyderabad, India
}

\begin{abstract}
The Poly Cystic Ovaries Syndrome is considered to be most prevalent of all endocrine disorders which women face. The purpose of our study was to collect data on how many women had awareness of this syndrome. Furthermore what was the ratio of women who were aware of these disorder symptoms was evaluated. Data was collected from three hundred women who were seeking education in ST.Ann's Degree College. Subjects were inquired through survey forms about the symptoms. The collected data was then interpreted to find the awareness of about PCOS as $63 \%$ out of 300 subjects. Regarding menstruation $21.1 \%$ had some sort of irregularity. $14.4 \%$ women had oligomenorrhoea. To conclude this study does not have sufficient evidence to establish the prevalence of PCOs through ultrasonography; thus only awareness on PCODS and prevalence of oligomenorrhoea and hirsutism has been stated which can serve as a guideline towards finding the true prevalence PCOS in our society.
\end{abstract}

\section{INTRODUCTION}

The term polycystic ovarian disease was first described by Irwing stein and Michael leventhal as a triad of "Amenorrhea", "Obesity" and "Hirsutism" in 1935 when they observed the relation between obesity and reproductive disorders [1].It is hence known as the "Stein-Leventhal syndrome" or Hyper androgenic anovulation (HA).It is the most common endocrine disorder affecting 2-3\% women of reproductive age worldwide [2].It is referred as "syndrome O", over nourishment, over production of insulin, ovarian confusion and ovulary disruption. PCODS is currently considered as a lifestyle disorder and it is complicated by chronic anovulatory infertility and hyper androgenism with the clinical manifestation of oligomenorrhoea, Hirsutism and acne [3]. As the symptoms of PCODS emerge insidiously and they coincide with normal puberty developments and PCODS problem may not be realized in the early stages and it may account for the failure to identify the problem in young women.

Poly cystic Ovarian Syndrome or PCOS is condition in which women's level sex hormones estrogens and progesterone are out of balance. This leads to growth of ovarian cysts. It causes problems with women's menstrual cycle, cardiac function and appearance. PCOS is the common female disorder. Globally prevalence estimates of PCOS are highly variable ranging from $2.2-26 \%$. There are limited studies of PCOS in India, the observational studies carried out by endocrinologists, gynaecologists and dermatologists relate to diverse aspects of PCOS. Most adolescents do not take the issue to doctors until the problem persists. Many studies have been carried out in hospital setups and recently a few studies have been carried outside India.

PCODS is on the rise because of lifestyle and environmental changes occurring with modernization .It is possible to identify the PCODS problem in late puberty and early adolescence. Initially PCODS can be identified by menstrual irregularities, excessive weight gain, excess facial hair growth, thinning of hair and acne. The varying prevalence of PCOS is mainly due to using different diagnostic criteria, heterogeneous nature of symptoms

In view of this and the fact that PCODS is unrecognized disorder occurring in the adolescent girls, a study has been carried out to check the 
awareness of student community of St.Ann's College for women, Hyderabad.

\section{The main objective of this study is to:}

1. To find out the level of awareness among the girl students about the symptoms of PCODS

2. To identify the adolescents who are at the risk of PCODS and sending them/suggesting for clinical testing.

The major purpose of this study is to create awareness about PCODS and help them to modify their life status and not to face future problems of infertility.

MATERIAL AND METHODS:

This study is a questionnaire based study on the awareness of PCODS. The participants are undergraduate students of the St.Ann's College for women. A total of 20 questions were asked to (250) girl students from the various departments in the college and the age group was between 18-20 years. Girls aged 18-20 years who attained menarche more than 4 years before the study, who were unmarried, willing to participate in the study were enrolled. Data was compiled and graphs were plotted. The data collected from the students were complied in the form of graphs representing the awareness of PCODS problem among the student community, family history of diabetics and cardiovascular diseases, discomfort during the menstrual cycle, primary symptoms and secondary symptoms of the PCODS problem.

Fig 1, Fig 3, Fig 4 shows the awareness about the PCODS among the student community, primary symptoms of PCODS, secondary symptoms of PCODS.

\section{Awareness about PCOD's among Student community}

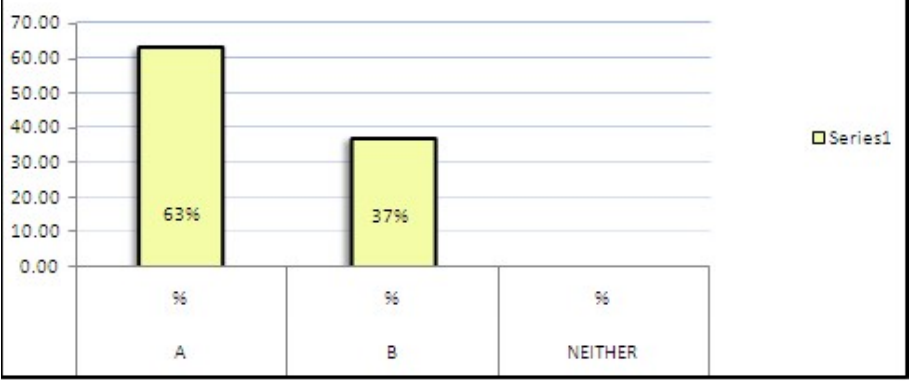

Information regarding the menstrual cycle.

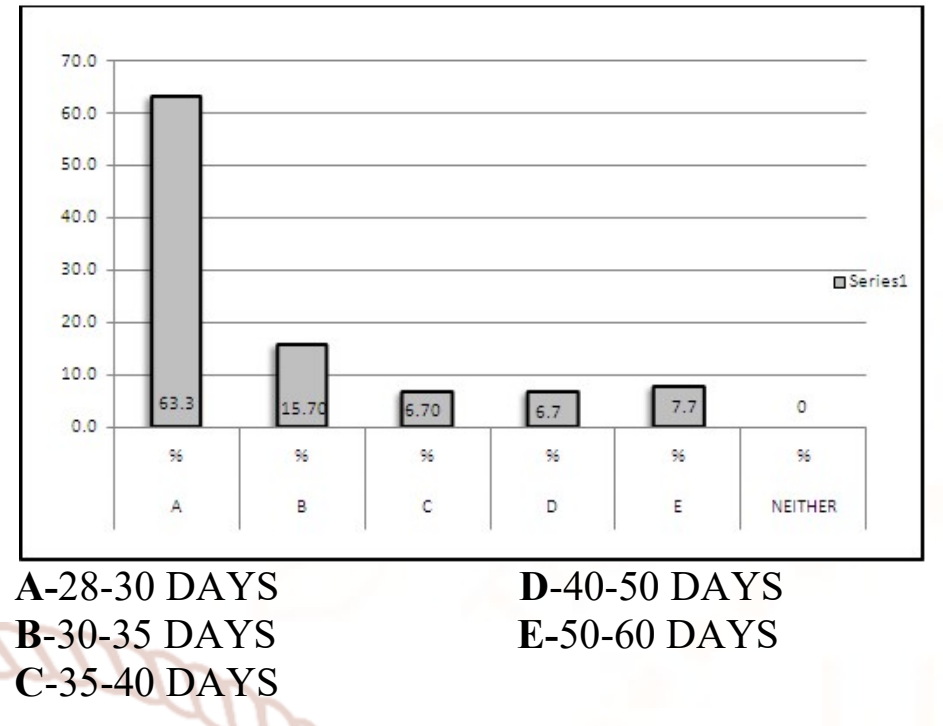

\section{Primary symptoms:}

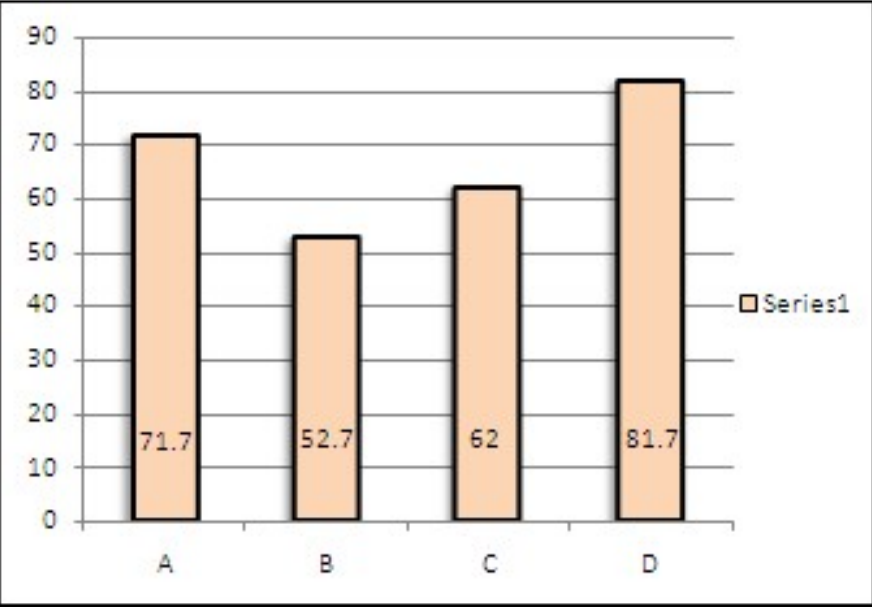

A-Hirsutism B-Oily hair/skin, dandruff on hair

C-Hair loss D-Abnormal weight gain

\section{Secondary Symptoms of PCOD:}

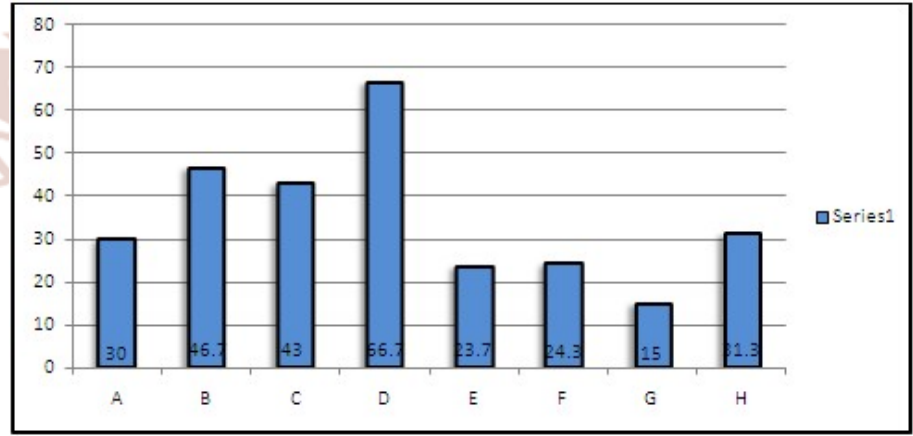

A- Insomnia.

B- Emotional instability.

C- Irritated mood swing.

D- Tiredness or fatigue.

E- Increased appetite.

F- Cystic acne.

$\boldsymbol{G}$ - Velvety spots.

$\boldsymbol{H}$ - Abdominal bloating. 


\section{RESULTS AND DISSCUSSION:}

1. Primary symptoms from the data collected from college students shows only $63 \%$ of people are aware of this syndrome. When students were asked about menstrual cycle $63.3 \%$ have their periods between $28-30$ days, $15.7 \%$ have their periods between 30-35 days, $6.7 \%$ have their periods between 40-45 days and only $7.7 \%$ have between 50-60 days.

2. The normal menstruation is usually occurs at the age of menarche $<16$ days with length of cycle is 24-32 days and length of flow is 3-7 days ad mount of bleeding $<80 \mathrm{ml}$. The normal cycle relies on the action and interaction of hormones released from hypothermal-pituitary ovarian axis and their effect on the endometrium. Many students during the survey revealed that information delivered in health education classes do not include information on normal or abnormal menstrual cycles and they were interested to know about that information and they can make decisions regarding the medical help. $40 \%$ people complained about discomfort about the menstruation period so the $40 \%$ students wee suggested to go clinical testing.

3. The students were asked about the abnormal hair on upper lip or chin and back. $28.3 \%$ students have complained about abnormal hair on upper lip or chin or back.

Hirsutism is excessive growth of facial or body hair on women. It can be seen as coarse dark hair that may appear on the face, chest, abdomen, back, upper arms or upper legs.

It is medical disorder associated with the hormones called androgens, excessive androgens.

The students were also questioned about the oily skin / hair / dandruff, 52.7\% have complained about oily skin/ hair/dandruff. Acne or excess oil on the skin is side effect brought by excess of testosterone and it is unfortunate side effect of hormonal acne. Dandruff is one of the markers of PCOD and it is not due to dry skin in PCOD patients. PCOD's skin /hair problems are caused by the seborrheic dermatitis which is due to hormonal imbalances.

Student's community of $68 \%$ reported about the hair loss/ thinning of hair on the scalp. This problem is isolated to PCOD's. The women with PCOD's suffer with the problem of hair loss/thinning/hair on scalp due to excess of testosterone levels. The dehydrotestosterone hormone is produced by the testosterone conversion. DHT produced binds the hair follicles and hair follicles will not grow as they have entered the resting phase. The hair follicles have entered into resting phase but they are still alive so some treatment can be used to reactivate the hair follicle.

During the survey an abnormal weight gain was reported by $81.7 \%$ people. Many students complained about the difficulty staying at their ideal weight. Obesity increases the risk of co-morbidities associated with PCOD's such as impaired glucose tolerance and type 2 diabetes mellitus, hyperlipedemia and arterial hypertension.

Family history of diabetics and cardiovascular also have been checked and $43 \%$ have responded positive and informed about the problem among their parents.

\section{Secondary Symptoms:}

1. Sleeping Disorders (Insomnia)

2. Mood Swings

3. Fatigue/Tiredness

4. Thick velvety spots

5. Increased craving for sugars

6. Cystic acne during periods

7. Emotionally unstable

8. Abdominal bloating

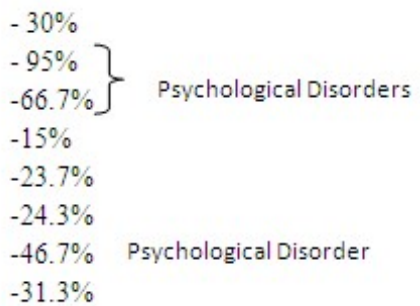

Women with PCOs are likely to suffer from a varietyof sleep disturbances including insomnia and obstructive sleep apnea. This is more observed during the menstrual cycles.

The study evaluated psychological disorders like mood swings $-95 \%$ (which comprises of anger, depression etc) which may caused by the menstrual disorders / irregular ovulation/cysts/fluid filled sacs which may be manifested as PCOs at later stages as PCOs are strongly associated with the psychological disorders.

\section{CONCLUSION:}

Ultrasonographies were not employed to diagnose cysts present in ovaries nor were other clinical parameters used to establish clinical hyperandrogenism thus we can not exactly calculate PCOS prevalence in our college. But an attempt has been made to find levels of menstrual irregularities, oligomenorrhoea and hirsutism which can be predictive of oligoovulation, anovulation and hyperandrogenism respectively.

The subjects are mostly young and do not have understanding of the disease to the extent they should. 
Although many women are affected by the polycystic ovary syndrome, difficulties associated with its uniform diagnosis persist. Efforts to heighten the profile of PCOS among the general public remain critical, as "minimal awareness" or "no awareness" of PCOS was present among $>10 \%$ of this motivated sample of unscreened subjects. A disease awareness campaign or an educational intervention is the need of the hour.

\section{REFERENCES:}

1. PCOS: Symptoms and Awareness in Urban Pakistani Women Somia Gul*, Syeda Adeeba Zahid, Almas Ansari Faculty of Pharmacy, Jinnah University for Women, Karachi, 74600, Pakistan

2. Longitudinal weight gain in women identified With polycystic ovary syndrome: Results of an observational study in young women Authors: Helena J. Teede, Anju E. Joham, Eldho Paul, Lisa J. Moran, Deborah Loxton, Damien Jolley, Catherine Lombard

3. Anxiety and depression in polycystic ovary syndrome: a comprehensive investigation Amanda A. Deeks, Ph.D, Melanie E. GibsonHelm, M. Rep. Sci., Helena J. Teede, Ph.D

4. Seminar on Polycystic ovary syndrome Robert J Norman, MD, Didier Dewailly, MD, Richard S Legro, MD, Dr Theresa E Hickey, PhD

5. Diagnostic and treatment characteristics of polycystic ovary syndrome: descriptive measurements of patient perception and awareness from 657 confidential self-reports, Mark Perloe, Michael J Tucker, Carolyn Kaplan, Marc Georges Genton and Glenn L Schattm $B M C$ Women's Health20011:3

Received: 11 July 2001,Accepted: 22 August 200 1,Published: 22 August 2001

6. Cronin L, Guyatt G, Griffith L, et al: Development of a health related quality of life questionnaire for women with polycystic ovary syndrome (PCOS). J Clin Endocrinol Metab. 1998, 83: 1976-87.

7. Kelly CJ, Connell JM, Cameron IT, Gould GW, Lyell H: The long term health consequences of polycystic ovary syndrome. Br J Obstet Gynaecol. 2000, 107: 1327-38.

8. Jancin B: Targeting primary care providers: endocrine society aims to raise PCOS awareness. Ob. Gyn News. 2000, 37

9. A Prospective Study of the Prevalence of the Polycystic Ovary Syndrome in Unselected Caucasian Women from Spain Miryam Asunción, Rosa M. Calvo, José L. San Millán, José Sancho, Sergio Avila, and Héctor F.Escobar-Morreale ,Received: September 08, 1999Accepted: March 19, 2000First Published Online: April 25, 2011

10. Solomon CG. 1999 The epidemiology of polycystic ovary syndrome. Prevalence and associated disease risks. Endocrinol Metab Clin North Am. 28:247-

11. Polson DW, Adams J, Wadsworth J, Franks S. 1988 Polycystic ovaries-a common finding in normal women. Lancet. 1:870-872.

12. Koivunen R, Laatikainen T, Tomas C, Huhtaniemi I, Tapanainen J, Martikainen H. 1999 The prevalence of polycystic ovaries in healthy women. Acta Obstet Gynecol Scand. 78:137-

13. . Zawadzki JK, Dunaif A. 1992 Diagnostic criteria for polycystic ovary syndrome: towards a rational approach. In: Dunaif A, Givens JR, Haseltine F, Merriam GR, eds. Polycystic ovary syndrome. Boston: Blackwell; 377-384.

14. Raj SG, Thompson IE, Berger MJ, Taymor ML. 1977 Clinical aspects of the polycystic ovary syndrome. Obstet Gynecol. 49:552-556 